\title{
Análisis de la Expresión del Receptor del Estrógeno en Endometrio de Ovejas Alimentadas con Dieta Normal y Dieta Suplementada
}

\author{
Analysis of the Expression of Estrogen Receptors in the Endometrium \\ of Ewes Fed with Normal and Supplementary Diet \\ "Adriana Vasconcellos C.; "*Marco Paredes H.; "* Eduardo Barrientos V.; \\ ***Yoselyn Olmazábal S.; ** Daniela Núñez R.; "** Javiera Navarrete V. \& **Benedicto Molina E.
}

VASCONCElloS, C. A.; PAREDES, H. M.; BARRIENTOS, V. E.; OLMAZÁBAL, S. Y.; NÚÑEZ, R. D.; NAVARRETE, V. J. \& MOLINA, E. B. Análisis de la expresión del receptor del estrógeno en endometrio de ovejas alimentadas con dieta normal y dieta suplementada. Int. J. Morphol., 27(4):1093-1098, 2009.

RESUMEN: Los efectos de la nutrición en reproducción ovina han sido estudiados por numerosos autores. Principalmente, el interés se ha centrado en los efectos de la calidad de la dieta ya que en ovinos sometidos a planos nutricionales bajos se ha observado anormalidades del embrión, fase lutea inadecuada, deficiencia en el aporte de progesterona al útero y falla en los mecanismos que comprenden el reconocimiento materno a la preñez. Existen trabajos sobre la relación alimentación-hormonas sin embargo la información existente sobre los receptores de hormonas esteroidales endometriales, indispensables para que ellas actúen, es muy escasa. El objetivo del presente estudio fue analizar comparativamente la expresión del receptor de estrógenos (RE) en el endometrio de ovejas en ciclo alimentadas con dieta suplementada y dieta normal. La expresión de la proteína receptora y del transcrito se detectó mediante análisis inmunohistoquímico y RT-PCR en tiempo real respectivamente. Los resultados muestran expresión inmunohistoquímica en zonas glandulares y carunculares, destacándose una intensa inmunorreacción en núcleos de células estromales y del epitelio glandular. Se detecto mayor expresión del transcrito del RE en endometrio de ovejas alimentadas con suplemento respecto a las que no recibieron suplemento alimenticio. Se discute el posible uso de esta información para aplicarla en programas de mejoramiento reproductivo en ovinos.

PALABRAS CLAVE: Oveja; Endometrio; Receptor de estrógeno; Receptor de progesterona; Nutrición.

\section{INTRODUCCIÓN}

Los efectos de la nutrición en reproducción han sido ampliamente estudiados (O’Callaghan \& Boland, 1999). La nutrición afecta a una cadena de eventos que se extienden desde la gametogénesis a la preñez. En ovinos la población folicular es muy sensible a los factores nutricionales por ejemplo, la foliculogénesis y la tasa promedio de ovulación puede aumentar bajo la manipulación nutricional (Scaramuzzi et al., 2006). El estado morfofuncional del tracto genital de las ovejas hembras es determinado por las hormonas sexuales, las que actúan a través de receptores intracelulares específicos. Se ha visto que la progesterona interactúa con su receptor en el útero y que la respuesta celular al esteroide depende de la cantidad de receptores presentes (Clark et al., 1992). Por lo tanto mecanismos que modifican el nivel de expresión de receptores pueden controlar la acción hormonal.

Los receptores de estrógeno juegan un importante papel en la regulación de los receptores de progesterona (Clark \& Mani, 1994). Se ha observado que ovejas sometidas a un plano de nutrición bajo muestran una disminución de la sensibilidad del endometrio a progesterona debido a una baja expresión de receptor de estrógeno cuya activación es necesaria para activar la trascripción del gen

\footnotetext{
* CEBIOR (Centro de Biotecnología en Reproducción).

${ }^{*}$ LINBA (Laboratorio de Investigación en Biotecnología Animal), Departamento de Ciencias Básicas, Universidad de La Frontera, Temuco, Chile.
} 
del receptor de progesterona (Abecia et al., 2006). La baja expresión del RE producirían además cambios en la sensibilidad endometrial a las hormonas esteroidales lo que en estadios de preñez tempranos impediría un desarrollo uterino adecuado, situación que afectaría a la implantación y sobrevida del embrión (Lozano et al., 1997; Sosa et al., 2004; Abecia et al.).

\section{MATERIAL Y MÉTODO}

Animales utilizados y obtención de muestras biológicas. La investigación se realizó con animales de 2 a 4 años de edad, mantenidos en el Campo Experimental Maquehue de la Universidad de La Frontera, Región de la Araucania, Chile. Se utilizaron ocho ovejas Criollas Araucanas divididas en dos grupos de cuatro individuos. Ambos grupos fueron mantenidos a pastoreo a bases de pradera mixta con ballica perenne y trébol blanco. Adicionalmente uno de los grupos tuvo acceso diariamente después del pastoreo a una suplementación con 250 g/día de grano de avena y 30 g/día de proteína cruda. La etapa del ciclo estral fue confirmada por anamnesis, estudio histológico y medición de concentraciones de progesterona y estrógeno en sangre (datos no mostrados). Después del sacrificio se extrajo el sistema reproductor y separaron los dos cuernos uterinos, unos de los cuales se fijó en Bouin acuoso, para su estudio inmunohistoquímico y el otro se congeló en nitrógeno líquido para extracción de ARN.

Análisis inmunohistoquímico. Las muestras fijadas se incluyeron en Paraplast (Merck, Alemania) y posteriormente se prepararon cortes de 5 micras a partir del tejido incluido. Los cortes se procesaron eliminado el Paraplast con xilol y posteriormente hidratándolos mediante incubación en una batería de concentración decreciente de etanol. Posteriormente, se eliminó la actividad de peroxidasas endógenas incubando con $\mathrm{H}_{2} \mathrm{O}_{2}$ al $3 \%$ en metanol por 10 minutos. Se lavó luego, dos veces con tampón fosfato salino (PBS) por 5 min. cada vez y se procedió a incubar los cortes en solución de bloqueo (BSA 1\% y tritón X-100 0,3\%, diluidos en PBS) a temperatura ambiente por 30 minutos. Los cortes se incubaron a continuación con el anticuerpo policlonal antiRE (H-184; Santa Cruz Biotechnology, USA) diluidos 1:500, en solución de bloqueo durante 12 horas a temperatura ambiente. Posteriormente los cortes se lavaron 3 veces por 5 min. cada vez con PBS. En adelante se utilizó el sistema de detección LSABTM Kits (Dako, USA) el cual se basa en el reconocimiento del primer anticuerpo por un segundo anticuerpo anti-IgG conjugado a biotina el cual interacciona específicamente con el complejo estreptoavidina conjugada a peroxidasa. Los lavados y tiempos de incubación se efec- tuaron de acuerdo a las instrucciones del fabricante del kit. El revelado se realizó incubando en solución DAB $(0,5 \%)$ y perhidrol $(1 \mathrm{ml} / \mathrm{ml})$ en PBS, a temperatura ambiente por $5 \mathrm{a}$ 10 min. La muestra histológica se lavó con agua destilada y seguidamente se tiño para contraste nuclear, con hematoxilina. Seguidamente, se deshidrató en una batería creciente de etanol y se diafanizó con xilol. Finalmente los cortes se montaron con resina Entellan (Merck). El análisis microscópico y captura de imágenes digitales se efectuó utilizando un microscopio Leitz, Laborlux 12.

\section{Análisis de expresión del transcrito de RE por RT-PCR} en tiempo real. El nivel de expresión del transcrito de RE en el endometrio de oveja, se evaluó por medio de RT-PCR en tiempo real mediante el método "Comparative $\mathrm{Ct}(\Delta \Delta \mathrm{Ct})$ " implementado en el sistema de amplificación en tiempo real "Step One" de Applied Biosystem (USA). Para esto, se extrajo inicialmente RNA a partir de cuerno uterino según metodología descrita por Chomczynski \& Sacchi (1987) con pequeñas modificaciones. Para estimar la concentración del RNA obtenido se utilizó la ecuación $[$ RNA] $=$ OD260 $x$ FD x $40 \mu \mathrm{g} / \mu \mathrm{l}$, donde FD es el factor de dilución utilizado y OD260 la absorbancia medida a $260 \mathrm{~nm}$. Mientras que la pureza se evaluó mediante la razón de absorbancia OD260/ OD280, considerado valores de de 1,8 a 2 como buena estimación de pureza. El RNA obtenido se utilizó para preparar ADN complementario (cDNA) mediante el uso del kit "High Capacity RNA to cDNA kit" (Applied Biosystems; USA). Para ello, se utilizaron $2 \mu$ g de RNA total mezclándolo con $5 \mu \mathrm{l}$ de tampón RT $2 \mathrm{X}$ y $0.5 \mu \mathrm{l}$ del mezcla de enzimas $20 \mathrm{X}$ provistos por el fabricante del kit. La mezcla de reacción se completó a $10 \mu 1$ de volumen final con agua ultrapura y se incubó a $37^{\circ} \mathrm{C}$ por 60 minutos, para finalmente detener la reacción incubando a $95^{\circ} \mathrm{C}$ POR 5 minutos. El cDNA obtenido se utilizó como templado para la detección y amplificación específica del RE y de b-actina cuya expresión constitutiva se utilizó como control endógeno referencial para la cuantificación relativa del transcrito de RE. El cDNA del RE se amplificó por PCR en Tiempo Real, mezclando $1 \mu \mathrm{l}$ de cDNA con $10 \mathrm{ml}$ del tampón de reacción Power SYBR Green PCR Master Mix 2X (Applied Biosystem), $1 \mathrm{ml}$ del partidor RE-S: CTCCACGATCAAGTCCACCT (10 mM), $1 \mathrm{ml}$ del partidor RE-A: ACGGAACCGAGACGATGTAG $(10 \mathrm{mM})$ y 7 $\mathrm{ml}$ de agua ultrapura para completar un volumen de reacción final de $20 \mathrm{ml}$. El cDNA de b-actina se amplificó mezclando $1 \mu \mathrm{l}$ de cDNA con $10 \mathrm{ml}$ del tampón de reacción Power SYBR Green PCR Master Mix 2X (Applied Biosystem), $1 \mathrm{ml}$ del partidor OBS: AACTCCATCATGAAGTGTGAC $(10 \mathrm{mM}), 1 \mathrm{ml}$ del partidor OBA: GATCCACATCTGCTGGAAGG $(10 \mathrm{mM})$ y $7 \mathrm{ml}$ de agua ultrapura completando un volumen de reacción final de $20 \mathrm{ml}$. 
Las secuencias de los partidores utilizados para el análisis del RE se derivaron a partir de la secuencias del cDNA del RE de oveja ( $\mathrm{N}^{\circ}$ de acceso AY033393) disponible en la base de datos GenBank asequible por medio del servidor web http://www.ncbi.nlm.nih.gov/ perteneciente al National Center for Biotechnology Information). Los partidores utilizados para amplificar el cDNA de b-actina se obtuvieron del artículo publicado por Dzidic et al. (2004). El diseño bioinformático de los partidores utilizados para amplificar el cDNA del RE se efectuó con el programa Primer 3 (http://primer3.sourceforge.net/). Las condiciones térmicas de amplificación para ambos genes fueron similares y se programaron con un ciclo inicial de 10 minutos a $95^{\circ} \mathrm{C}$, seguido por 45 ciclos compuestos cada uno por una denaturación a $95^{\circ} \mathrm{C}$ por 20 segundos, hibridación a $60^{\circ} \mathrm{C}$ por 20 segundos, y extensión a $72^{\circ} \mathrm{C}$ por 20 segundos. Se programó al término de los 45 ciclos de amplificación, un ciclo para el análisis de las temperaturas de fusión (melting) de los amplicones lo cual permitió evaluar la especificidad de la reacción de amplificación y descartar de este modo el efecto de productos no específicos sobre la cuantificación de los templados.

\section{RESULTADOS}

El análisis inmunohistoqumico del RE en el endometrio de ovejas adultas indica presencia de RE en diversa zonas del endometrio uterino. Se destaca inmunorreacción nuclear en células de glándulas endometriales (ga), estroma (es), epitelio (ep) y zona caruncular (ca). Aparentemente se denota mayor intensidad de la marca inmunorreactiva en endometrio de ovejas alimentadas con suplemento (Figs. 1B, E y H) respecto a las que se alimentaron con una dieta estándar (Figs. 1A, D y G).

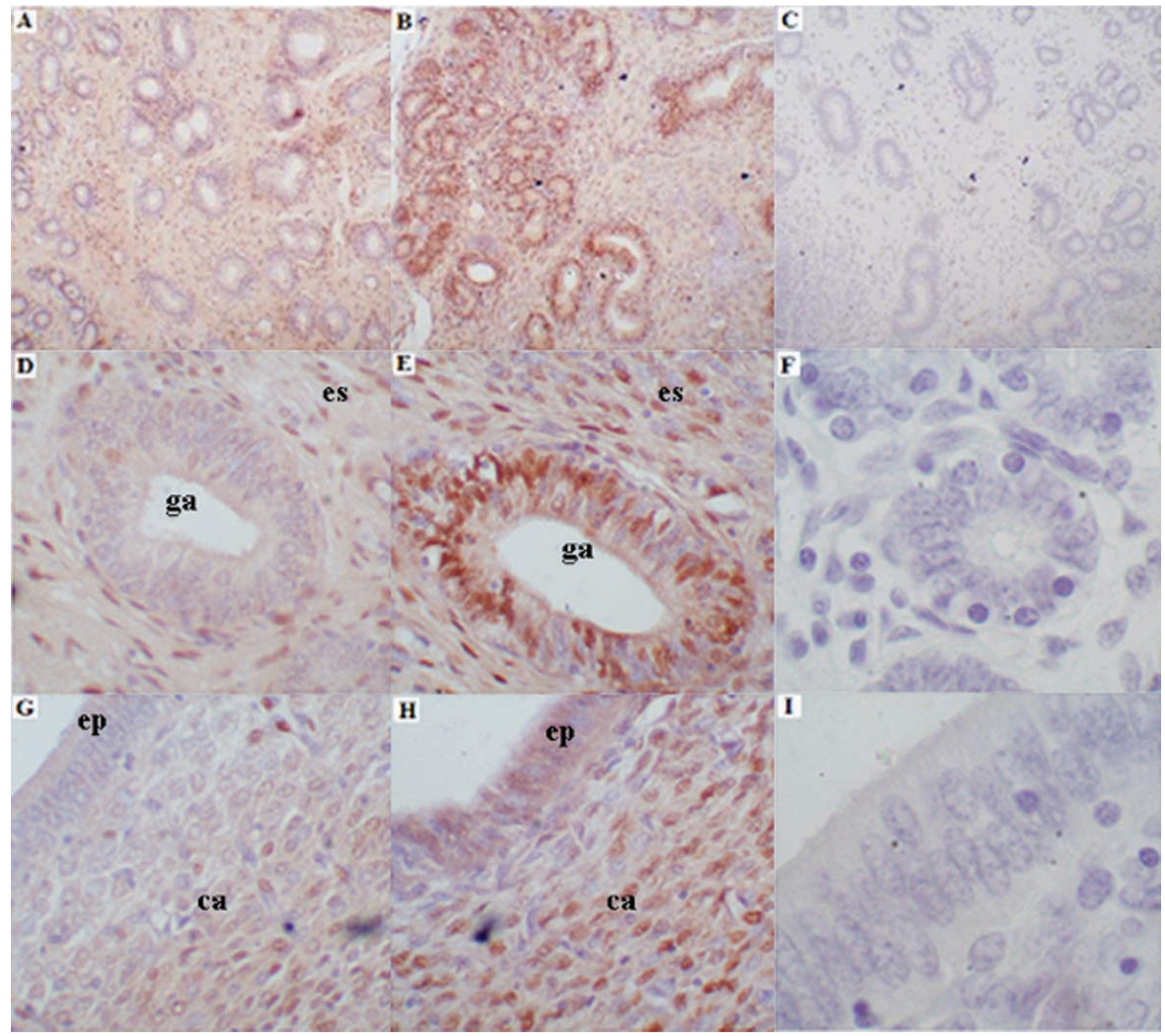

Fig. 1. Análisis inmunohistoquímico del receptor de estrógeno en endometrio de ovejas alimentadas con dieta estándar (A, D y G) y de ovejas alimentadas con dieta suplementada con carbohidratos y proteínas (B, E y H). En C, F e I, se muestran cortes incubados con suero pre-inmune (controles negativos). Se destacan zonas inmunorreactivas glandulares (ga), estromales (es), epiteliales (ep) y carunculares (ca) del endometrio uterino de la oveja. 
VASCONCELlOS, C. A.; PAREDES, H. M.; BARRIENTOS, V. E.; OLMAZÁBAL, S. Y.; NÚÑEZ, R. D.; NAVARRETE, V. J. \& MOLINA, E. B. Análisis de la expresión del receptor del estrógeno en endometrio de ovejas alimentadas con dieta normal y dieta suplementada. Int. J. Morphol., 27(4):1093-1098, 2009.

El análisis del nivel de expresión relativa del transcrito de RE indica que este se encuentra en mayor cantidad en endometrio de ovejas alimentadas con dieta suplementada respecto a las que fueron alimentadas con dieta estándar (Fig. 2).

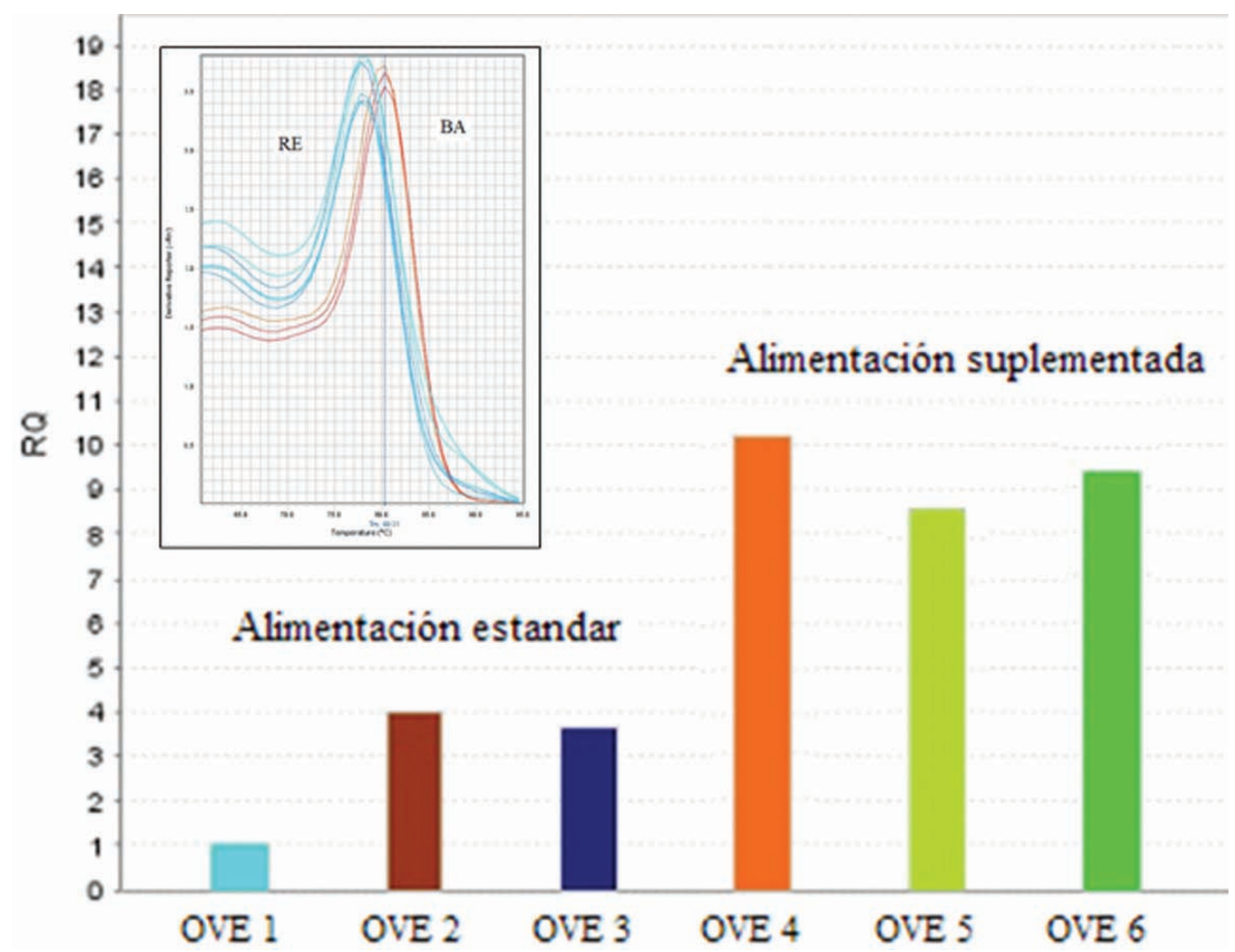

Fig. 2. Niveles de expresión relativa del ARNm del RE en endometrio de ovejas alimentadas con dieta estándar (OVE 1, OVE 2 y OVE 3) o dieta suplementada (OVE 4, OVE 5 y OVE 6). El recuadro interior muestra curvas de disociación de los productos de amplificación evaluados por RT-PCR en Tiempo Real correspondientes al gen referencial b-actina (BA) y al receptor de estrógeno (RE).

\section{DISCUSIÓN}

La nutrición constituye un factor importante que afecta la eficiencia reproductiva de los de los ovinos (O'Callaghan \& Boland; Meikel et al., 2004; Scaramuzzi et al.). Afecta sucesos desde la gametogenesis a la preñez. En ovinos la población folicular es muy sensible a los factores nutricionales y la foliculogénesis y tasa promedio de ovulación puede realmente aumentar bajo la manipulación nutricional (Scaramuzzi et al.). El estado morfofuncional del tracto genital de las ovejas hembras es determinado por las hormonas sexuales, las que actúan a través de receptores intracelulares específicos (Meikel et al., 2001, 2004). Los estrógenos y la progesterona inducen cambios que en el útero durante el periodo fetal, neonatal (Wiley et al., 1987), prepuber (Garofolo \& Tasende, 1996) y durante sus fases reproductivas (Cherny, 1991; Spencer \& Bazer, 1995; Meikle et al., 1997, 2001, 2004; Vasconcellos et al., 2005, 2006, 2009).
Los resultados obtenidos mediante el análisis inmunohistoquímico, muestran expresión del RE tanto en la zona caruncular como en la zona glandular del endometrio de cuerno uterino tanto enlas ovejas que recibieron suplementación alimenticia de carbohidratos y proteínas como de las que fueron alimentadas con una dieta estándar. Sin embargo la intensidad de la marca inmunoreactiva es evidentemente mayor en el endometrio de las primeras (Fig. 1). Existen datos que indican que ovejas alimentadas con un plano nutricional bajo muestran una disminución de la sensibilidad del endometrio a hormonas esteroidales, lo que en estadios de preñez tempranos impediría un desarrollo uterino adecuado, situación que afectaría a la implantación y sobrevida del embrión (Lozano et al.; Sosa et al., Abecia et al.).

Los resultados obtenidos mediante el análisis por RTPCR en tiempo real evidencian una mayor expresión del 
transcrito de RE en endometrio de las ovejas mantenidas con alimentación rica en carbohidratos y proteínas respecto a las ovejas que no recibieron una alimentación suplementada (Fig. 2). Esto podría deberse a diferencias en el factor de crecimiento insulínico tipo I (IGF-I), que disminuye en ovejas desnutridas. Se ha sugerido que el IGF-I estimula la expresión de RE, por lo que un bajo nivel nutricional puede resultar en una menor cantidades de RP en endometrio (Sosa et al.). En nuestro estudio observamos aumento de los RE endometriales en ovejas mantenidas con dieta suplementada lo que podría relacionarse con un mejor desarrollo uterino lo que a su vez afecta positivamente en la supervivencia y desarrollo del embrión y mejoraría las perspectivas de vida del recién nacido.

VASCONCELlOS, C. A.; PAREDES, H. M.; BARRIENTOS, V. E.; OLMAZÁBAL, S. Y.; NÚÑEZ, R. D.; NAVARRETE, V. J. \& MOLENA, E. B. Analysis of the expression of estrogen receptors in the endometrium of ewes fed with normal and supplementary diet. Int. J. Morphol., 27(4):1093-1098, 2009.

SUMMARY: The effects of nutrition on sheep reproduction have been studied by many authors. The interest has focused on the effects of diet quality in sheepin in which low plans $n$ have low plane nutrition can cause abnormalities of the ovum or the embryo, luteal inadequancy and failure of the supply of progesterone to the uterus or failurein the mechanisms involved maternal of pregnancy. There are papers about the relation food-hormones, however, the existing information on endometrial steroid hormone receptors, which are essential for them to act, is very scarce. The aim of this study was to comparatively analyze the expression of estrogen receptor (ER) in endometrial cycle of sheep fed diet supplemented and normal diet. The expression of the receptor protein and the transcript were detected by immunohistochemical analysis and RT real-time PCR, respectively. The results showed immunohistochemical expression of $\mathrm{RE}$ in glandular and carunculares areas, especially in an intense inmunorreacción stromal cell nuclei and glandular epithelium. Detected increased expression of transcripts of RE in sheep fed a supplement with respect to not receiving a dietary supplement. We discuss the possible use of this information for application in breeding sheeps programs.

KEY WORDS: Sheep; Endometrial; Estrogen receptor; Progesterone receptor; Nutrition.

\section{REFERENCIAS BIBLIOGRÁFICAS}

Abecia, J. A.; Sosa, C.; Forcada, F. \& Meikle, A. The effect of undernutrition on the establishment of pregnancy in the ewe. Reprod. Nutr. Dev., 46:367-78, 2006.

Cherny, R. A. Inmunohistochemical localization of estrogen receptors in the endometrium of the ewe. Reprod. Fertil. Dev., 3:321-31, 1991.

Chomczynski, P. \& Sacchi, N. Single-step method of RNA isolation by acid guanidinium thiocyanate-phenolchloroform extraction. Anal. Biochem., 162:156-9, 1987.

Clark, J. H.; Schrader, W. T. \& O'Malley, B. W. Mechanisms of action of steroid hormones. Williams Textbook of Endocrinology. ( $8^{\text {th }}$ Ed). Philadelphia, W.B. Saunders Comp., 1992. pp.35-90.

Clark, J. H. \& Mani, S. K. Actions of ovarian steroid hormones. In: The physiology of Reproduction. Knobil, E. \& Neill, J. D. (Eds). New York, Raven Press, 1994. pp.1011-59.

Dzidic, A.; Mohr, A.; Meyer, K.; Bauer, J.; Meyer, H. H. \& Pfaffl, M. W. Effects of mycophenolic acid (MPA) treatment on expression of $\mathrm{Fc}$ receptor $(\mathrm{FcRn})$ and polymeric immunoglobulin receptor (pIgR) mRNA in adult sheep tissues. Croat Med. J., 45(2):130-5, 2004.

Garofalo, E. G. \& Tasende, C. Uterine estrogen and progesterone receptors in prepuberal ewe: distribution in myometrium, endometrium, and caruncles. Vet. Res., 27:177-83, 1996.

Lozano, J. M.; Abecia, J. A.; Forcada, F.; Zarazaga, L. \& Alfaro, B. Effect of undernutrition on the distribution of progesterona in the uturus of ewes during the luteal phase of the estrous cycle. Theriogenology, 49:539-46, 1997.

Meikle, A.; Garófalo, E. G.; Rodríguez- Piñon, M.; Tasende, C. \& Sahlin, L. Regulation by gonadal steroids of estrogen and progesterone receptors along the reproductive trac in lambs. Acta Vet. Scand., 42:131-9, 2001.

Meikle, A.; Tasende, C.; Rodríguez, M. \& Garófalo, E. G. Effects of estradiol and progesterone on the reproductive trac and on uterine sex steroid receptors in female lambs. Theriogenology, 48:1105-13, 1997.

Meikle, A.; Tasende, C.; Sosa, C. \& Garófalo, E. G. The rol 
VASCONCELlOS, C. A.; PAREDES, H. M.; BARRIENTOS, V. E.; OLMAZÁbal, S. Y.; NÚÑEZ, R. D.; NAVARRETE, V. J. \& MOLINA, E. B. Análisis de la expresión del receptor del estrógeno en endometrio de ovejas alimentadas con dieta normal y dieta suplementada. Int. J. Morphol., 27(4):1093-1098, 2009.

of sex steroid receptors in sheep female reproductive physiology. Reprod. Nutr. Dev., 16:385-94, 2004.

O'Callaghan, D. \& Boland, M. Nutritional effects on ovulation, embryo development and the establishment of pregnancy in ruminants. Anim. Sci., 68:299-314, 1999.

Scaramuzzi, R. J.; Campbell, B. K.; Downing, J. A.; Kendall, N. R.; Khalid, M.; Muñoz-Gutiérrez, M. \& Somchit, A. A review of the effects of supplementary nutrition in the concentrations of reproductive and metabolic hormones and the mechanisms that regulate folliculogenesis and ovulation rate. Reprod. Nutr. Dev., 46:339-54, 2006.

Sosa, C.; Lozano, J. M.; Viñoles, C.; Acuña, S.; Abecia, J. A.; Forcada, F.; Fosberg, M. \& Meikle, A. Effect of plane of nutrition on endometrial sex steroid receptor expresión in ewes. Anim. Reprod. Sci., 84:337-48, 2004.

Spencer, T. E. \& Bazer, F. W. Temporal and spatial alterations in uterine estrogen receptor and progesterone receptor gene expression during the estrous cycle and early pregnancy in the ewe. Biol. Reprod., 53:1527-43, 1995.

Vasconcellos, A.; Paredes, M.; Carrasco, J. \& Núñez, D. Analysis of the Expression of Estrogen and Progesterone Receptors in the Endometrium of Ewes of the Races Romney Marsh and Araucana. Int. J. Morphol., 27(1):97100, 2009.

Vasconcellos, A.; Sepulveda, N.; Castillo, J. \& Rosas, C. Presencia de receptores de Estrógeno y de Progesterona en el Endometrio de ovejas prepúberes. Estudio inmunohistoquímico. Int. J. Morphol., 23(4):393-6, 2005.

Vasconcellos, C. A.; Sepúlveda, B. N. \& Pacheco, C. C. Presencia de receptores de estrógeno, progesterona y de CBG en el tracto genital de ovejas y de perras. Estudio inmunocitoquímico. Int. J. Morphol., 24(3):457-62, 2006.

Wiley, A. A.; Bartol, F. F. \& Barron, D. H. Histogenesis of the ovine uterus. J. Anim. Sci., 64:1262-9, 1987.
Dirección para correspondencia:

Dra. Adriana Vasconcellos Costa

Facultad de Medicina

Universidad de La Frontera

Casilla 54- D

Temuco - CHILE

Email. avascon@ufro.cl

Recibido : 22-08-2009

Aceptado: 23-09-2009 